\title{
NARRATIVAS BIOGRÁFICAS DE \\ MUJERES QUE HAN EXPERIMENTADO \\ VIOLENCIA DE PAREJA
}

\author{
Leidy Vanessa Vera Forero ${ }^{(a)}$ \\ Natalia Andrea Londoño Valderrama ${ }^{(b)}$ \\ Mayra Alejandra Ortegón Melo ${ }^{(c)}$ \\ Jenny Andrea Romero González ${ }^{(d)}$
}

\author{
BIOGRAPHICAL NARRATIVES OF WOMEN VICTIMS \\ OF INTIMATE PARTNER VIOLENCE
}

NARRATIVAS BIOGRÁFICAS DE MULHERES QUE

EXPERIMENTARAM VIOLÊNCIA DE CASAIS

Fecha de recepción: 19 de febrero del 2018

Fecha de aprobación: 21 de mayo del 2018

Disponible en línea: 20 de junio del 2018

\section{Sugerencia de citación:}

Vera Forero, L.V., Londoño Valderrama, N. A., Ortegón Melo, M. A., y Romero González, J. A. (2018). Narrativas biográficas de mujeres que han experimentado violencia de pareja. Razón Crítica, 5, 177-209 doi: http://dx.doi.org/10.21789/25007807.1357

\footnotetext{
(a) Psicóloga de la Universidad Santo Tomás, Colombia https:/ / orcid.org/0000-0002-7426-4688 leidyvera@usantotomas.edu.co

(b) Psicóloga de la Universidad Santo Tomás, Colombia https:/ / orcid.org/0000-0003-3445-7861

natalia.londono@usantotomas.edu.co

(c) Psicóloga de la Universidad Santo Tomás, Colombia https:/ / orcid.org/0000-0001-5272-3225

mayraortegonm@usantotomas.edu.co

(d) Magíster en investigación social interdisciplinaria de la Universidad Francisco José de Caldas y psicóloga de la Universidad Santo Tomás (sede Bogotá).

Docente de investigación tiempo completo y coordinadora de prácticas investigativas de la facultad de psicología de la Universidad Santo Tomás (Sede Villavicencio), Colombia https:/ / orcid.org/0000-0001-5309-8847

jenny.romero@usantotomas.edu.co
} 


\section{R E S U M E N}

El siguiente artículo tiene como objetivo comprender la construcción narrativa de la experiencia de violencia de pareja en torno a las relaciones de poder que se configuran en las historias de vida de mujeres que acuden a la Secretaría de la Mujer de Villavicencio por atención primaria psicológica. La investigación que da origen al artículo se desarrolló desde el método cualitativo, con un abordaje hermenéutico de tipo biográfico-narrativo. El paradigma de la complejidad junto al enfoque sistémico-narrativo, el constructivismo y el construccionismo social fueron guías para desarrollar la presente investigación. Desde estas perspectivas, el lenguaje es una herramienta posibilitadora de la construcción de la experiencia de violencia e historias de vida de las participantes. Las categorías abordadas son: la violencia de pareja, las relaciones de poder y la construcción narrativa. Entre los principales hallazgos del estudio se puede resaltar que las dinámicas de poder en las que se encontraban inmersas estas mujeres, en sus diferentes contextos, favorecieron la aparición de la violencia de pareja. Estas dinámicas ejemplifican expresiones de la cultura patriarcal en la que se destaca la supremacía del hombre sobre la mujer.

PALABRAS CLAVE: historia de vida y narrativa, relaciones de poder, violencia de pareja. 


\section{A B S T R A C T}

This article aims to understand experience-building of intimate partner violence around power relations in the life stories of women attending the Secretariat of Women in the city of Villavicencio (Colombia) looking for primary psychological care. The research which gave rise to this paper was developed based on the qualitative method and following a hermeneutical approach to biographicalnarrative. The paradigm of complexity along with the systemic-narrative approach, constructivism, and social constructionism were the guides to develop this study, considering they are based on the fact that language is a tool for enabling the construction of participants' experience of violence and life stories. Categories addressed in this work are: Intimate partner violence, power relations, and narrative construction. Among our main findings it can be highlighted that power dynamics experienced in different contexts by participating women favored the emergence of intimate partner violence, showing that such dynamics exemplify and reinforce expressions of the patriarchal culture in which male supremacy over women becomes a reality.

KEY WORDS: Life story and narrative, intimate partner violence, power relations.

\section{R E S U M O}

O seguinte artigo tem como objetivo compreender a construção da experiência da violência de casais em torno das relações de poder que se configuram nas históorias de vida de mulheres que ajudam a Ssecretaria da Mmulher de Villavicencio (Colômbia), por atenção primáaria psicológica. A investigação pesquisa se desenvolveu desde ocom base no método qualitativo, com uma abordagem hermenêutica de tipo biográfico- narrativo. O paradigma da complexidade junto com o enfoque sistêmico narrativo, com o construtivismo e com o construcionismo social, foram guias para desenvolver a presente investigaçãopesquisa, ao ser e a linguagem uma ferramenta possibilitadora na da construção da experiência de violência e históorias de vida das participantes. As categorias abordadas foram: a violência de casais, as relações de poder e a construção narrativa. Entre os principais resultados do estudo, podem-se se pode ressaltar as dinâmicas de poder em que essas mulheres se encontravam imersas essas mulheres nos diferentes contextos que favoreceram a apariçãoo surgimento da violência de casais e que legitimavam, legitimando algumas das expressões da cultura patriarcal, e nas que quais se destacam a supremacia do homem sobre a mulher.

PALAVRAS-CHAVE: construção narrativa, relações de poder, violência de casais, relações de poder e a construção narrativa. 


\section{N T R O D U C C I Ó N}

La violencia de pareja es una de las diversas manifestaciones de la violencia familiar con respecto a la cual han emergido múltiples lecturas interpretativas y explicativas. Una de ellas se encuentra vinculada con las relaciones de poder. Según esta interpretación, la violencia de pareja es vista como una pauta de dominación del "más fuerte sobre el más débil", apoyada en discursos culturales en los que usualmente la mujer es comprendida como el sujeto "débil" y se acentúa una interacción de dominación del hombre hacia la mujer (Martínez, 2014). En relación con esto, González y Fernández (2010, p. 98) afirman que "en la violencia de pareja, las más afectadas son las mujeres, debido entre otros aspectos a su situación de presentar un menor poder social y físico", lo que favorece la construcción de relaciones basadas en la desigualdad y legitima la presión del género masculino sobre el femenino, lo que da paso así a la naturalización de la dominancia masculina (González y Fernández, 2010).

Así mismo, diversos estudios señalan que las mujeres son las mayores afectadas por esta forma de violencia, como se puede constatar en el documento Estimaciones mundiales y regionales de la violencia contra la mujer, realizado por la Organización Mundial de la Salud (oms, 2013), en el que se estima que, en el mundo, el $30 \%$ de las mujeres han experimentado violencia de tipo física o sexual. En cuanto a la violencia psicológica, esta ha sido difícil de cuantificar debido a aspectos diferenciales entre países y culturas. Sin embargo, los datos existentes reflejan unos índices de prevalencia alta (Agencia de los Derechos Fundamentales de la Unión Europea, 2014). 
Las cifras recientes sobre este fenómeno apuntan a un panorama desalentador y en crecimiento. Ante este panorama se hace necesario abordar sus múltiples dimensiones, puesto que, como lo sugiere la Organización Mundial de la Salud (2002), a partir de la alta incidencia de la violencia se desarrolla un proceso de normalización en el que incluso se justifican este tipo de interacciones -se las asume como una forma válida de "proteger" y "defender el honor masculino", entendiendo así el uso de la fuerza sobre la mujer como un derecho que le es propio al hombre-.

Para la mayoría de los países de América Latina y el Caribe, el tema de violencia de pareja hacia la mujer se ha convertido en un problema de salud pública. Contamos con cifras muy significativas respecto al tema, como las del contexto de Colombia, que se configura como uno de los países con las tasas más altas de violencia física contra las mujeres en Latinoamérica. En Colombia, el 70\% de las mujeres ha experimentado en alguna medida violencia emocional o psicológica (López, 2016). En relación con lo anterior, Baquero, Guatequi y Sarmiento (citados en Ramírez, 2015) afirman que el maltrato hacia la mujer constituye un tema cotidiano en el país. Este maltrato suele emerger a partir de la apropiación de una cultura machista y se expresa en diferentes casos de violación de los derechos contra las mujeres.

En relación con el contexto en el cual se realizó la presente investigación, el Instituto Nacional de Medicina Legal y Ciencias Forenses indicó que Villavicencio, en el año 2016, se encuentra entre los cinco municipios más afectados a nivel nacional por el fenómeno de violencia de pareja (Instituto de Medicina Legal y Ciencias Forenses, 2017). Con base en esta información, el presente estudio realizó un análisis de la violencia de pareja desde la construcción narrativa de mujeres de esta región que acudían a atención psicológica primaria en la Secretaría de la Mujer por estos hechos violentos. Estas mujeres decidieron compartir voluntariamente su historia de vida y su experiencia de violencia.

La violencia de pareja representa un fenómeno de amplio espectro que, como previamente se mencionó, ha venido en aumento y que, a partir de ciertas ideas estereotipadas, se llega a normalizar y naturalizar. Esto es muy preocupante si se contempla lo dicho por Contreras (2016) en su columna sobre "la normalización de la violencia” para el periódico virtual Excélsior: "Vivimos en 
un entorno tan salvaje, que se comienza a aceptar que la violencia es una herramienta válida para resolver problemas. El peligro es que se ha vuelto común y lo común -con el tiempo- comienza a considerarse correcto" (Contreras, 2016).

Entre los diversos elementos que están involucrados en este fenómeno, es marcado el discurso patriarcal de la sociedad, que permea a todas las organizaciones y los sistemas, favoreciendo el establecimiento de relaciones de poder en las que se presentan relaciones de dominación/subordinación (Villarreal, 2001). Así mismo lo afirma la Organización Mundial de las Naciones Unidas (ONU) en la Declaración sobre la eliminación de la violencia contra la mujer, Resolución de la Asamblea General 48/104 del 20 de diciembre de 1993, en la cual:

\begin{abstract}
Reconoce que la violencia contra la mujer constituye una manifestación de relaciones de poder históricamente desiguales entre el hombre y la mujer, que han conducido a la dominación de la mujer y a la discriminación en su contra por parte del hombre e impedido el adelanto pleno de la mujer, y que la violencia contra la mujer es uno de los mecanismos sociales fundamentales por los que se fuerza a la mujer a una situación de subordinación respecto del hombre (p. 2).
\end{abstract}

A partir de esto, y comprendiendo que la violencia de pareja es un fenómeno de gran amplitud en el que están en juego varios elementos, se visibiliza la importancia de tomar como categoría de análisis en esta investigación las relaciones de poder, pues estas logran cubrir una serie de elementos que se consideran propios en el contexto en el que la investigación se desarrolló. Al respecto, Montes (2008) afirma que la violencia de pareja en torno a las relaciones de poder se encuentra también atravesada por la dominación social, puesto que, en la cultura patriarcal, los hombres pueden tener un poder desproporcionado sobre las mujeres que está sustentado a su vez en estereotipos sociales y jerarquías basadas en el género que dan un mayor estatus al hombre.

En el marco de esta investigación se exploraron las narrativas que construyeron las mujeres en relación a su experiencia de violencia de pareja, así como las relaciones de poder más significativas que construyeron a lo largo de su vida en los 
sistemas en los que se encontraban inmersas. Esto permitió, a su vez, identificar la relación entre la experiencia de violencia y las relaciones de poder en el marco de la construcción narrativa.

Se tomó la construcción narrativa como una forma de acercamiento al fenómeno que permite conocer la interpretación que le dan los sujetos a su vida, así como a la forma en que se comprenden a sí mismos y a los otros (Clandinin, Debbie y Murray, 2007). Teniendo en cuenta que algunas de las mujeres que viven este tipo de experiencias deciden acudir a instituciones en busca de atención psicológica o jurídica, esta investigación se desarrolló en la Secretaría de la Mujer de Villavicencio, entidad que hace parte del sector de protección en la ruta de atención integral municipal de violencia basada en género.

A fin de llegar a la comprensión de este fenómeno desde la propia experiencia de quienes lo han vivido surge la siguiente pregunta: ¿Cómo las mujeres que acuden a la Secretaría de la mujer de Villavicencio por atención primaria psicológica construyen narrativamente la experiencia de violencia de pareja en torno a las relaciones de poder?

\section{Marco referencial}

\section{Marco paradigmático y epistemológico.}

El abordaje paradigmático para el objeto de estudio de esta investigación se establece a partir del pensamiento sistémico complejo, bajo los principios epistemológicos del construccionismo social y el constructivismo, nociones que se resisten a los planteamientos causales-lineales, permitiendo comprender la construcción dinámica e interaccional de la violencia de pareja en torno a las relaciones de poder.

De acuerdo con este paradigma "observamos y comprendemos la realidad, reconociendo la complejidad, particularidad y experiencia única de los sistemas" (Acosta y Cardozo 2014, p. 15). Siguiendo estos lineamientos, la presente investigación se interesó en comprender la construcción y configuración narrativa de la violencia de pareja a partir de los relatos de las mujeres en torno a su experiencia particular. 
El paradigma de la complejidad permite llegar a una comprensión de la violencia de pareja a partir de los tres principios propuestos por Morín (1990). El principio dialógico plantea que los antagónicos también son complementarios, es decir, que no existe lo uno sin lo otro. En la dinámica de pareja, estos puntos dialógicos y antagónicos se pueden ver en los tipos de interacciones que establece la pareja. De acuerdo con Zuluaga (2007), estas interacciones pueden ser simétricas (mutua interdependencia, igualdad de poder) y complementarias (mayor poder para uno y aceptación por parte del otro).

El principio de recursividad organizacional, por su parte, hace referencia a un proceso "en el cual los productos y los efectos son, al mismo tiempo, causas y productores de aquello que les produce" (Morín, 1990, p. 106). Desde esta comprensión circular, la cultura, entendida en el macrosistema, permite apreciar cómo los discursos patriarcales y micromachistas que predominan en el contexto de la región se producen e influyen en la violencia de pareja y, así mismo, cómo la violencia de pareja favorece la producción de estos discursos patriarcales y micro machismos. Por último, el principio hologramático invita a ver el todo en la parte y la parte en el todo. La idea del holograma "trasciende al reduccionismo que no ve más que las partes, y al holismo que no ve más que el todo" (Morín, 1990, p. 107). En el marco de esta investigación, este principio se visualiza a través de los relatos narrativos de las mujeres, los cuales son singulares -les son propios- pero a su vez hacen parte del todo, puesto que representan los discursos comunales en tanto que sus narrativas son construidas a partir de la interacción con varios sistemas.

Con las nociones epistemológicas de esta investigación se otorga especial importancia a la construcción de la realidad por medio de procesos internos con los que las mujeres participantes significan su realidad social (constructivismo). Se considera así mismo que, aunque estas experiencias son únicas y hacen parte de su propia construcción de la realidad, también se crean y se reproducen a través de la cultura y el contexto en el que cada individuo se encuentra (construccionismo social). De acuerdo con Sluzki (citado en Feixas y Villegas, 2000, p. 24), "cada uno de nosotros lleva consigo un mapa del mundo, una representación o una concepción que conduce a construir lo que se percibe de modo que pase a ser percibido como realidad”. 
Así pues, en esta investigación se reconoce el compuesto social en la construcción de la realidad y la función esencial del lenguaje que Anderson (1997) y Echeverría (2005) entienden como generador, pues da orden y sentido a nuestra vida y a nuestro mundo, al tiempo que es el medio través del cual los seres humanos se crean a sí mismos.

\section{Marco disciplinar}

A continuación se encuentran las categorías de análisis abordadas.

\section{Construcción narrativa.}

Las narrativas, como menciona Echeverría (2005, p. 228), "son tejidos lingüísticos interpretativos que [...] procuran generar sentido y establecen relaciones entre las entidades, las acciones y los eventos de nuestro mundo de experiencias". Las narrativas permiten entonces dar sentido a las experiencias que se viven. Cuando el sujeto actúa muchas veces lo hace a partir de una determinada narrativa dentro de la cual se confiere sentido a las acciones. Es así como Echeverría (2005, p. 228) menciona que:

Las narrativas nos proporcionan una base desde la cual actuamos en el mundo. Según el tipo de narrativa que sustentemos, nuestras posibilidades de acción serán diferentes. Estos son tejidos lingüísticos interpretativos que, como tales, procuran generar sentido y establecen relaciones entre las entidades, las acciones y los eventos de nuestro mundo de experiencias. Por lo tanto, que podamos hablar también del poder del lenguaje haciendo referencia al poder de nuestras narrativas.

Por su parte, White (2004, p. 31) habla del proceso de significación dentro de la narrativa al establecer una relación entre significado y narrativa:

La idea de significación que las personas atribuyen a su experiencia es lo que determina sus vidas, es a través del relato o la narración o la historia lo que suministra el marco primario 
a la interpretación, a la actividad de dar sentido o significación y que es por obra de los relatos o historias como las personas juzgan sus propias vidas y las vidas de los demás al encontrar sentido en su experiencia.

Por lo anterior, es través de la construcción narrativa de las historias de vida que las participantes de esta investigación configuraron significados y le dieron sentido a diferentes experiencias que han vivido a lo largo de sus vidas.

\section{Violencia de pareja.}

La violencia de pareja, según Gómez, Murad y Calderón (2013), se puede manifestar en violencia física, violencia psicológica y violencia sexual.

La violencia física se refiere a aquella que representa "riesgo o disminución de la integridad corporal de la persona" (Gómez, Murad y Calderón, 2013, p. 19). Este tipo de violencia, según Quintela, Arandia y Campos (2004, p. 26), comprende “desde los golpes más leves hasta las palizas de muerte o intento de asesinato, en una gradación que puede variar en frecuencia e intensidad".

La violencia psicológica, según Martos (citado en De Luján, 2013, p. 326), "no es una forma de conducta, sino un conjunto heterogéneo de comportamientos, en todos los cuales se produce una forma de agresión psicológica”. Al respecto, la Alta Consejería Presidencial para la Mujer (citada en Galeano, Jaimes y Palacio, 2014, p. 50) describe algunas de estas conductas:

Violencia psicológica [...] a nivel de violencia en la pareja, se identifica celos por parte del conyugue, control constante de dónde se encuentra la mujer, acusación de infidelidad, ignorar a la mujer e impedir el contacto con amigos y/o amigas; así mismo incluye amenazas por parte de su pareja como abandonarla, quitarles a sus hijos o quitarle el apoyo económico.

Por último, la violencia sexual se refiere a aquella en la que se lleva a cabo una actividad sexual entre dos o más personas y una de las partes implicadas no ha dado su consentimiento o aprobación para la realización de dicho acto sexual. Incluso aunque no se haga uso de la fuerza ni de la coacción, esta representa una clara forma 
de violencia, puesto que representa de alguna manera la anulación de las personas y vulneración de su derecho a la libertad (De Lujan, 2013).

\section{Relaciones de poder.}

Una relación de poder no se manifiesta necesariamente como una expresión de violencia. Como afirma Hernández (2007, p. 288):

Una relación de poder no es por naturaleza ni la manifestación de un consenso ni la expresión de la violencia [...] Una relación de poder implica la pertenencia a un sistema en el que hay niveles jerárquicos de regulación, de control y de acatamiento; estar inscrito en una jerarquía social en la que alguien hace hacer algo a otro o le hace ser eso que él es.

Para efectos de esta investigación, es importante explorar las relaciones de poder que permean las múltiples interacciones en las que se involucran los sujetos y que pueden haber emergido en su relación de pareja. En este caso, se configuran dinámicas interacciónales de violencia en las que se visualiza el ejercicio de este poder. Según Amigot (2005), estas relaciones de poder surgen también a partir de los esquemas establecidos en la sociedad patriarcal, en la que es el hombre quien, a lo largo de la historia y en mayor medida, ha buscado integrar a la realidad algunos símbolos de poder (Bateson, citado en Hernández 2007). En las interacciones de pareja se puede visibilizar el poder a partir de la asimetría en la relación, con respecto al lugar de la mujer.

\section{Método}

La investigación utilizó un método cualitativo de segundo orden de corte hermenéutico que "se interesa por los significados, que son interpretados a partir de la observación y la voz (narración) de los agentes/actores, es decir conocer los hechos humanos a través de la experiencia humana, tal y como ha sido vivenciada" (Bolívar, citado en Aponte, 2016, p. 216). Esta hermenéutica fue de tipo biográfico-narrativo, el cual se caracteriza por "la descripción de la re-historia, de la estructura narrativa y de las variedades de la experiencia” (Huchim y Reyes, 2013, p. 9). Este tipo de estudio 
permitió a las participantes contar sus propias vivencias, para luego ser interpretadas y leídas con las investigadoras a la luz de los marcos previamente propuestos en la investigación.

\section{Participantes.}

Las participantes fueron mujeres mayores de edad que sufrieron violencia de pareja y acudieron a la Secretaría de la Mujer por atención primaria psicológica. A continuación, se realizará una descripción de cada participante:

- Participante 1. Nelly: Mujer de 31 años con un hijo de 8 años. Ella manifestó haber experimentado violencia de pareja durante los 9 años de convivencia con su expareja, vivenciando violencia física, sexual y psicológica a lo largo de su relación.

- Participante 2. Xiomi: Mujer de 35 años, madre soltera de dos hijos, manifiesta haber experimentado violencia de pareja en su primera relación marital.

- Participante 3. Ángela: Mujer de 37 años, tiene 2 hijos con los cuales no convive. Manifiesta haber experimentado violencia de pareja con el padre de su segundo hijo con quien convivió 11 años.

- Participante 4. Sara: mujer de 34 años, convive con su segundo esposo hace 12 años y con sus hijos del su primer matrimonio. Mantiene convivencia conflictiva con su pareja actual, quien ha ejercido y ejerce violencia hacia ella.

- Participante 5. Nannis: mujer de 28 años, tiene 2 hijos. Manifiesta que experimentó situación de violencia en su relación de pareja, que terminó recientemente.

\section{Técnicas de recolección, construcción y análisis de la información.}

La narrativa conversacional, la historia de vida y la entrevista a profundidad se convirtieron en las principales técnicas para la recolección de la información. Las entrevistas se realizaron entre los meses de septiembre y noviembre del año 2017 en las instalaciones de la Secretaría de la Mujer de la ciudad de Villavicencio. Se realizaron tres encuentros de forma individual con cada una de las participantes, con una duración aproximada de 1 hora y 30 minutos 
cada uno. Posteriormente, la información grabada en audio fue trascrita de manera literal y organizada en líneas de intervención, en una matriz de transcripción. Finalmente, para organizar la información se construyeron matrices de análisis, de acuerdo a las categorías y subcategorías propuestas en la investigación. Estas fueron analizadas por un proceso de triangulación sistemática entre: relato-interpretación y teoría.

Tabla 1. Guión entrevistas

\begin{tabular}{|c|c|c|c|}
\hline & Temas & Descripción & Material de apoyo \\
\hline \multirow{3}{*}{$\begin{array}{l}\text { Historia de } \\
\text { vida }\end{array}$} & $\begin{array}{l}\text { Historia } \\
\text { personal }\end{array}$ & $\begin{array}{l}\text { Descripción de ella misma. } \\
\text { Identificación. } \\
\text { Proyecciones. }\end{array}$ & $\begin{array}{l}\text { Tarea de la primera sesión: } \\
\text { escribir su historia de vida. }\end{array}$ \\
\hline & $\begin{array}{l}\text { Historia } \\
\text { familiar }\end{array}$ & $\begin{array}{l}\text { Dinámicas familiares. } \\
\text { Estructura, rituales familiares, } \\
\text { costumbres (genograma). } \\
\text { Recuerdos familiares. } \\
\text { Experiencias. } \\
\text { Relaciones de poder en la familia } \\
\text { o violencia intrafamiliar. }\end{array}$ & $\begin{array}{l}\text { Segunda sesión: } \\
\text { fotografías. }\end{array}$ \\
\hline & $\begin{array}{c}\text { Relatos de } \\
\text { vida sobre } \\
\text { relaciones } \\
\text { enmarcadas } \\
\text { en la } \\
\text { violencia }\end{array}$ & $\begin{array}{l}\text { Situaciones de crisis, violencia. } \\
\text { Efecto que tiene la problemática } \\
\text { en su vida. } \\
\text { Influencia de esas concepciones } \\
\text { en su vida y relaciones. }\end{array}$ & \\
\hline \multirow[t]{2}{*}{$\begin{array}{l}\text { Relaciones } \\
\text { de poder }\end{array}$} & Social & $\begin{array}{c}\text { Apreciar cómo dichas prácticas } \\
\text { hacen parte de su vida. } \\
\text { Relación con amigos, vecinos } \\
\text { y compañeros de trabajo } \\
\text { (contexto). } \\
\text { Valores patriarcales. } \\
\text { Opinión del rol de la mujer. } \\
\text { Opinión del rol del hombre. } \\
\text { Ubicación de la mujer en el } \\
\text { ámbito laboral. } \\
\text { ¿Cómo debe ser la mujer? } \\
\text { ¿Cómo debe ser el hombre? }\end{array}$ & \\
\hline & Familiar & $\begin{array}{c}\text { Dinámicas familiares. } \\
\text { Toma de decisiones en el hogar. } \\
\text { Aporte de cada integrante al } \\
\text { hogar. } \\
\text { Funciones que considera, } \\
\text { desde su experiencia, que debe } \\
\text { cumplir la mujer en la familia. } \\
\text { Funciones que, desde su } \\
\text { experiencia, considera que el } \\
\text { hombre debe cumplir en la } \\
\text { familia. }\end{array}$ & \\
\hline
\end{tabular}




\begin{tabular}{|c|c|c|c|}
\hline & Temas & Descripción & Material de apoyo \\
\hline $\begin{array}{l}\text { Relaciones } \\
\text { de poder }\end{array}$ & Interpersonal & $\begin{array}{c}\text { Relación con su pareja actual } \\
\text { y relaciones anteriores (si las } \\
\text { hubo). } \\
\text { Indagar acerca de la teoría } \\
\text { que se tiene de la agresión } \\
\text { masculina. } \\
\text { Causas, ideas de por qué } \\
\text { ocurrieron los episodios } \\
\text { particulares de violencia entre } \\
\text { ellos. } \\
\text { Hablar sobre la ideología } \\
\text { patriarcal. Rol del hombre y } \\
\text { mujer. } \\
\text { Narrar experiencias de violencia. }\end{array}$ & $\begin{array}{c}\text { Noticias sobre } \\
\text { feminicidios. } \\
\text { Noticias sobre violencia } \\
\text { de pareja }\end{array}$ \\
\hline \multirow{4}{*}{$\begin{array}{l}\text { Violencia de } \\
\text { pareja }\end{array}$} & Psicológica & $\begin{array}{l}\text { Identificar sucesos que } \\
\text { contengan: } \\
\text { Insultos, chistes ofensivos, } \\
\text { gritos, prohibiciones, control } \\
\text { económico, manipulaciones. }\end{array}$ & \\
\hline & Sexual & $\begin{array}{l}\text { Presionar u obligar a mantener } \\
\text { relaciones sexuales en contra de } \\
\text { su voluntad }\end{array}$ & \\
\hline & Física & $\begin{array}{l}\text { Identificar la utilización de la } \\
\text { fuerza física. }\end{array}$ & \\
\hline & Social & $\begin{array}{l}\text { La violencia se hace evidente } \\
\text { para las demás personas del } \\
\text { entorno social }\end{array}$ & \\
\hline
\end{tabular}

\section{Discusión de resultados}

A continuación se expondrá la discusión de algunos de los resultados obtenidos en la construcción de las historias de vida narradas y escritas por las participantes a lo largo de los encuentros.

Frente a la violencia de pareja, algunas de las mujeres expresan lo siguiente:

Ángela: Durante mi convivencia con él fue más de tristeza que

felicidad. Tenía muy mala bebida y se portaba grosero y agresivo y era malhumorado. A pesar de eso convivimos 13 años porque no quería que mi otro hijo creciera sin un papá.

Xiomi: El papá de mi hijo... no, yo creo nosotros nunca fuimos una familia, porque eso no fue un hogar, eso fue un suicidio, porque eso era golpe tras golpe, tras golpe, uno no sabía ni qué era eso. 
Sara: Me siento en cierta manera como en una cárcel, porque tengo que decir, eh... para dónde voy, qué voy hacer, cómo me puedo parar, cómo me puedo sentar, qué puedo hablar, qué no puedo decir. Como si fuera de cierta manera, no sé, inválida, discapacitada de algo, no sé... así me siento.

Estos relatos reflejan lo que mencionan Hayati et al. (citados en Molina y Moreno, 2015): ante la tensión y el conflicto que experimenta la mujer, se construyen pautas que favorecen la permanencia en la relación. Vemos así que las participantes relatan haber convivido varios años con su pareja, por lo que la pauta violenta fue ritualizada haciéndose parte de la cotidianidad y de las vidas de las víctimas. En el relato de Sara se puede ver cómo su discurso interpreta y da cuenta de lo que es su situación actual, mientras que los relatos de las otras participantes, que ya atravesaron esta situación, muestran un análisis más totalizador de su experiencia y convivencia con su pareja ante la violencia.

Se puede apreciar en los relatos de las mujeres la manifestación de las tres formas de violencia de pareja planteadas en esta investigación. Cada una de las participantes resalta el significado de acuerdo a su experiencia. En cuanto a la violencia física, todas identificaron haber vivido por lo menos un episodio de violencia física. Así lo narran en los siguientes fragmentos:

Nelly: Y después, cuando... eh, pues, cuando me pegó así fue cuando, a comienzo de año, fin de año, me pegó una patada acá (señala las piernas), me reventó el labio y me [golpeó] por acá (señala el cuello) tenía morados, porque como él intentaba era ahogarme (señala el cuello).

Xiomi: Eso me daba en el piso, me botó al piso y me golpié [sic.] tan duro con una baranda que estaba en el piso, en la cabeza, que yo quede como tonta, como... yo sentía que pegaba pero como que no reaccionaba al verlo a él y como que no pude tomar aire.

Ángela: ... Yo le dije "trae el niño", así.. y yo no sé el qué me entendió o qué, y se bajó y empezó “esta triplehijue...” y yo no sé qué, “imala madre! 
va dejar el niño botado", y me coronó un puño acá en la frente, eso me negrió [sic.] toda esta parte (señala sus pómulos y mejillas).

Así mismo, en sus narraciones resaltaron cómo las agresiones representaron un riesgo para su integridad física. Esto se relaciona con lo que plantean Gómez, Murad y Calderón (2013), quienes indican que las agresiones tienden a aumentar. Esto ocurrió en las relaciones de las participantes, en las que en algunos episodios se llegó al uso de objetos cortopunzantes como cuchillos, lo que les hacía creer que sus vidas se encontraban en riesgo:

Nelly: Una vez sí, me acuerdo tanto que él me cogió en la pieza en una
esquina así con un cuchillo delante del niño. Ángela: Yo no viví más con el papá de él porque el último problema que tuvimos me cogió con un cuchillo, me iba matar, borracho. Yo dije "no, si el sigue asi un día de estos voy a terminar ensartada en ese cuchillo", y él estaba negociando que un revolver porque en ese tiempo estaban robando mucho fincas. Yo dije "no, si me cogió con un cuchillo ahora un revolver, no".

Xiomi: Ese día por solo responderle una cachetada, por un puño que él me dio, eso me cogió y casi me mata esa vez. Casi me mata, la... me dejó que no podía ni respirar.

La violencia-agresión que puede emerger en las relaciones simétricas se puede apreciar en el relato de vida de la participante Xiomi, puesto que cuenta que hubo un momento en la relación en el que se presentó agresión tanto de su expareja hacia ella como de ella hacia él. En tal caso, la pauta de interacción se hizo mayormente simétrica (Perrone y Nannini, 2000). Se puede apreciar también cómo, a partir de la llamada escalada, se llega a una simetría inestable en la que uno se impone sobre el otro generando una inconformidad en este último que lo lleva a buscar cómo mantener su posición (Bateson, citado en Feixas, Muñoz, Compañ y Montesano, 2016) que hace a la experiencia de violencia más significativa: 
Xiomi: Al principio yo no me defendía, yo me dejaba. Eso me ponía la cara (expresión de desaprobación)... hasta que una vez yo dije "no más, yo no tengo que dejarme pegar más", y fue peor, me fue peor.

La violencia psicológica se pudo visualizar en ofensas, manipulaciones, restricciones, celos y amenazas, situaciones que las participantes relatan haber vivenciado por parte de su pareja:

Sara: Él me decía que... me gritaba "si usted está a mi lado, usted no puede estudiar, nada de amistades, olvídese. Tendría que quedarse sola para hacer lo que usted quiera”. Entonces por eso, por eso no inicié clase.

En la reelaboración de la experiencia de violencia, la participante Xiomi parece aceptar el discurso con el que su pareja se refiere a ella y considerarlo como verdadero:

Xiomi: Entonces él ya no me pegaba, pero me maltrataba verbalmente. Me insultaba, me decía unas palabrotas horribles, me decía que yo no valía nada, que yo... era peor que una escoria, que yo era peor que la hierba que nace en no sé dónde, eso me decía. Que yo era una maleza, que yo era una mujer bruta, ignorante, que yo no habia tenido estudio y por eso yo no era nadie en la vida, y que nunca lo iba a ser... Y bueno, yo creo que fue cierto (risas).

Con este fragmento se puede comprender la narrativa como dirigente de la experiencia del ser humano en un espacio y tiempo determinado. En este contexto las palabras son creadoras de sucesos que tienen contenidos transformables. Las personas, a partir de sus narraciones, dan cuenta de su construcción, no solo individual, sino colectiva (González y Serna, 2004). Por otra parte, se pudo apreciar cómo en la violencia psicológica se encuentran discursos de poder del hombre hacia las mujeres, discursos en los cuales es él quien tiene el poder sobre sus vidas:

Ángela: Él me ofendía mucho, me ofendía mucho. Nada de lo que yo opinaba era bueno, todo era malo y todo era lo que él dijera, y yo era todo lo que él dijera y ya. 
Xiomi: Y después de que el niño nació, eso fue la primera vez que me pegó, después de que el niño nació eso me... yo no podía salir sin decir para dónde, tener un horario de ida y un horario de llegada.

Sara: Me siento mal... me siento mal porque yo no vivo mi vida como yo quisiera, sino la vivo al gusto de otra persona (silencio).

En acuerdo con lo anterior, Kaufman (citado en Ramírez y Posso, 2012) afirma que, en el marco de las relaciones de poder del hombre hacia la mujer, "la equiparación de la masculinidad con el poder, ha conformado y ha justificado a su vez la dominación de los hombres sobre las mujeres en la vida real y su mayor valoración sobre éstas". Sara, por ejemplo, menciona que:

Cuando yo digo que quiero estudiar, cuando yo digo que quiero ser alguien en la vida... [él:] "pero usted quien va ser, usted solo nació para ser perra o puta”. Bueno, esos son los términos.

En este tipo de interacción se ven involucradas las pautas relacionales de la interacción simétrica y complementaria descritas por Bateson (citado en Feixas, Muñoz, Compañ y Montesano, 2016). En el anterior relato se ve cómo la interacción complementaria se hizo rígida, lo cual impide el desarrollo de quien ocupa la "posición inferior". En este sentido, Amurrio, Larrinaga, Usategui y Del Valle (2010) afirman que en la violencia de pareja existe una asimetría en la dominación que se construye socialmente, por lo que significa ser femenino y masculino; y culturalmente es la dominación masculina la que predomina en este juego de roles. Por ejemplo, la participante Nelly manifiesta tener al comienzo una interacción complementaria en la que su pareja recurría a una posición de superioridad y ella de aceptación e inferioridad al optar por el silencio:

Nelly: Pues hay veces [que] yo no le decía nada, porque yo... ya, si yo le decía algo, una cosa, él ya empezaba a echarme madrazos; ya empezaba por ahi a la violencia entoes [sic.] a gritarme.

En el trascurso del relato de Nelly, se puede visualizar el efecto de escalada que se produce en las relaciones simétricas según 
Bateson (citado en Feixas, Muñoz, Compañ y Montesano, 2016). Concorde con este fenómeno, Nelly opta por una posición que conlleva a la situación en la que uno suele imponerse al otro, pero el otro no se acaba de conformar y lucha por mantener su posición, creando una simetría inestable:

Nelly: ... él todo me lo transmitía, entonces yo me volvi como así, también como es él, ¿̇si? Él me decía una grosería, entonces yo no me quedaba callada y yo se la respondía. Sí, pues porque... pues él me lo hizo.

Nelly: ... empezó a insultarme "que no sé qué, que no sé cuántas", entoes [sic.] yo no le ponía cuidado. Pero después, ya con el tiempo, yo me aguanté mucho, entoes [sic.] yo le respondi "ay, ya, que esto y lo otro". Entoes [sic.] ahi empezamos a choques a choques.

Nelly: Ya me decía hasta "zorra", "perra", "no sé qué”. Nosotros ya, ya después... y eso fue como una escala, ya solo golpes.

De acuerdo con Lavilla, Cabrero y Jimeno (2011, p. 7), en "la violencia psicológica se podría incluir el maltrato social (aislamiento), el económico (presión y exigencias de carácter económico-monetario), y otras conductas que vulneran la libertad personal":

Sara: ... he visto que él cuándo he querido dejarlo se me ha llevado los papeles, mis documentos, o si he tenido plata se me la ha llevado, o si no por algún motivo me ha chantajeado, hablándolo así.

Sara: O sea, él que quería por cualquier momento o cualquier cosa tenerme, o sea, les gusta una persona de esas es hacer presión, sea de la comida, sea de una ropa, sea de un arriendo, sea por alguna enfermedad, y más si uno no tiene estudio, entonces le dice usted es una ignorante, usted es una estúpida, usted no vale nada, usted es una perra, usted la miran, usted es una cualquiera.

Ángela: ... Él no sabía llenar los cheques entonces yo se los llenaba. Pero él era que decía "esto se compra", "esto también". O sea, él era el que disponía de la plata, yo no. 
La violencia psicológica fue narrada como la más significativa y emotiva. En algunos de los relatos las participantes expresan que es el tipo de violencia que más las afecta, y que inclusive preferían el maltrato físico:

\begin{abstract}
Ángela: Es más duro y más... yo a veces prefiero mil veces que me den una cachetada, [y no] que de pronto me estén sacando las cosas en cara o toda ahora. O sea, las humillaciones o que lo traten mal a uno, eso es horrible.
\end{abstract}

Sara: Pero yo le digo a él... le reprocho. La verdad yo le reprocho porque yo le digo a él "si usted me quisiera, usted no, ni me humilla, ni me trata mal, ni me irrespeta", porque no solo el irrespeto físico, es el irrespeto de la moral, el ofenderlo a uno, en agredirlo a uno con las palabras, en hacerlo sentir menos.

Xiomi: No me maltrataba física, pero sí mental y verbal. Porque en ese tiempo si por ser como decía él una ignorante, no... entonces él me decía muchas cosas y él me hacía sentir muy mal, y yo lloraba y lloraba, y un día dije no más, a él lo trasladaron y yo aproveché y me fui.

Frente a las diferentes manifestaciones de violencia de pareja que experimentaron las participantes y construyeron en sus narrativas, es importante resaltar que las tres participantes que culminaron el proceso experimentaron algún episodio de violencia sexual narrado, en los términos de Corsi (1994), como contacto sexual no consentido:

Nelly: Y llegó todo borracho y, y... y quería que yo estara con él, y... y que... y que... y que le hiciera eso allá, sí, y que me masturbara y que lo masturbara, y que me dejara venir en la cara. Pero no... me obligó a hacer eso y yo no quería. Le dije que no, que yo no quería hacer eso porque no me gusta, eso lo hacen las, las viejas esas. Yo le dije que no y me dijo que sí, y me agarró duro me hizo así (cogió del cabello y la acerco a sus partes intimas) y yo pues... pues yo no, yo no, yo no, yo no, le demostraba así, como, como pues ya.

Xiomi: Cuando yo no quería estar con él, me pegaba en las piernas porque tenía que estar con él asi yo no quisiera. 
Ángela: Si [me obligó a tener relaciones sexuales]... (silencio), y me decía cosas muy duras, entonces no las escribi ahí, pero sí... o sea, como si "con ellos se dejó, ¿por qué no se va dejar de mi??" Como si... me hacía sentir como si yo hubiera disfrutado en vez de yo haber sufrido, como si yo fuera disfrutado.

Además de esto, es importante destacar que para las participantes hubo dificultades en la identificación de la violencia sexual. Esto habla a su vez de la naturalización de este tipo de violencia en la pareja, que se asocia con el cumplimiento de los roles establecidos en la relación.

Frente a lo anterior, Chávez (2013, p. 7) argumenta que "los actos de violencia sexual contra las mujeres por parte de sus parejas quedan sumidos y atrapados en la paradoja de lo público y privado, ocultos tras el velo que limita entre ambos lugares”. Así mismo, Noseda (2015) afirma que la violencia sexual en la pareja, por la existencia de construcciones sociales en las cuales se visibiliza a la mujer como un objeto sexual, productor de placer y reproductor, terminan naturalizando prácticas sexuales como "normales" o inadvertidas por la mujer.

Dentro de los relatos de las participantes pudieron identificar relaciones de poder en las que han interactuado a lo largo de su vida. El poder constituye un aspecto que hace parte de todas las relaciones sociales de los sujetos, por lo que dichas relaciones de poder pueden apreciarse desde diferentes dimensiones como la familiar, la interpersonal (de pareja) y la social. En lo que atañe a la dimensión familiar, se logran identificar diferentes narrativas de las mujeres en las que se ven las relaciones de poder que se reflejan también en el discurso patriarcal en el cual está inscrita la dominancia de lo masculino sobre lo femenino (Villareal, 2001):

Nelly: Pues mi mamá no trabajaba pues porque nos cuidaba a nosotras.

Si, y [a] mi papá tampoco le gustaba que saliera a trabajar.

Ángela: Ellos se creen con la autoridad de mandar porque aportan un dinero. O sea, yo lo veo así "iyo soy el que pongo!".

Nanis: Pues, mi mamá, ella no estaba de acuerdo con que él nos dejara encerrados y se hiciera lo que él dijera. Pero pues, como uno antiguamente era criado a lo que dijera el hombre en la casa, no se compartía de que lo 
que se dijera en la pareja, sino que, si el papá decía no, la mamá entonces "qué podemos hacer, no".

Se puede apreciar en los fragmentos anteriores cómo se identifican las construcciones que hace cada participante acerca del rol del hombre y la mujer en la dinámica familiar. En cuanto a las relaciones de poder en la pareja, se pueden apreciar los siguientes fragmentos:

Nelly: Cuando yo me junte con el papá de mi hijo, él casi no me dejó trabajar, no me dejaba trabajar.

Ángela: A veces cuando se iba a trabajar así y llegaba como acalorado quería las cosas ya. Quería tener todo servido, sino se ponía bravo. Yo hacía lo que el papá de Damián dijera y ya eso se hacía y ya.

Sara: Actualmente, como él me mira que yo tengo otras posibilidades, o sea, yo trabajo por mi misma, entonces ya tanta manipulación no puede haber. De cierta manera he aprendido a leer un poco más, a escribir un poco más. Entonces como que ya mira otro aspecto frente a mí.

Xiomi: Él siempre me pegaba que porque yo no le servía rápido, que porque no le ponía las botas ahi ilustradas [sic], que porque no le limpiaba las placas, que porque no le abria la puerta la puerta a penas él pitaba la primer vez en la moto. Yo tenía que ser el celador de las 24 horas de la casa para que no me pegara.

Es importante enfatizar de nuevo el discurso patriarcal que permea las diferentes relaciones sociales y que permite que se dé una legitimización del control y sometimiento de las mujeres (Quintanilla, 2014). Así mismo, Jimeno (citado en Vera, 2015) entiende la violencia como un hecho social que está presente en una variedad de escenarios, situaciones encadenadas, relaciones, actores y procesos de aprendizaje de la cultura. Argumenta que hay personas, creencias, valores, expectativas, formas de comunicación y acciones individuales e institucionales relacionadas especialmente con la violencia. Es en ese marco que suceden la violencia doméstica y los abusos de autoridad, experiencias diarias que han sido incorporadas con elementos de índole cultural y organización de una sociedad: 
Xiomi: La mamá de él se daba de cuenta, los hermanos se daban de cuenta. Antes me lo ayudaban a quitar pero, pues, nadie decía nada, porque como él era un funcionario público.

Ángela: Era en la madrugada, cuando llegaron que necesitaban el carro, entonces lo amenazaron y de una vez a mi me violaron... (Silencio) $Y$ él se fue con la condición de que no nos hicieran nada a nosotros, y que él se iba y a él se lo llevaron, y ahí fue cuando ellos abusaron de mí.. (silencio) (Relato de la participante sobre violación por parte de un grupo de las FARC).

Lo anterior se puede comprender con respecto a la forma en que "los hombres hacen uso de los privilegios otorgados por el machismo para lograr un buen desempeño y conservar el control, manejando una actitud de 'tener que vencer', 'estar encima de las cosas, y dar órdenes'” (Kaufman, citado en Ramírez y Posso, 2012). Así, pues, al hombre, a través de los diferentes supuestos sociales y culturales, se le atribuye la labor de "estar encima de", por lo que se ve inmerso en una serie de sucesos en los que se ratifica su poder, en este caso sobre la mujer.

En torno a la categoría de construcción narrativa se aprecian diferentes construcciones interpretativas que las participantes realizan de su experiencia y a las que le otorgan sentido. De acuerdo con White (2004, p. 31), el proceso de significación dentro de la narrativa "es lo que determina sus vidas, es a través del relato o la narración o la historia lo que suministra el marco primario a la interpretación”. En este sentido, las participantes llegaron a significar su experiencia de la siguiente manera:

Xiomi: Uno no merece absolutamente nada de eso. Que eso es una gran mentira usted misma decirse que es que usted se lo merece.

No, usted no se merece que la traten mal, usted no se merece que la insulten, usted no se merece que la golpién [sic.], porque es que usted, usted no pidió eso ni se lo merece.

Ángela: Yo quería para Damián lo que no me tocó a mí.. que crecer sin un papá, que le pasara igual que a mí. Que crecer sin un papa, porque yo sentía que eso le hacía falta. Pero no quise seguir sacrificando más, un 
día me va terminar matando... yo a veces me pongo a mirar que a veces con un papá o sin un papá sigue siendo el mismo.

Sara: Como que en cierta manera yo me he preguntado misma y me he sentido en deuda, y en cierta manera cuando él se molesta él me grita "es que yo le he dado mi plata", "es que yo le he dado de comer", "es que yo le aportado..., la apoyo con sus hijos, o sea, ni ese hijuetantas del papá de sus hijos”... (silencio) así.

En cada uno de los fragmentos anteriores se ve que las participantes construyeron significados de acuerdo con sus acontecimientos de vida, una interpretación de su situación y experiencia. En concordancia con lo anterior, White (2004) menciona que la actividad de dar sentido o significación define la forma en la que las personas juzgan sus propias vidas y las vidas de los demás, encontrando sentido en su experiencia.

Xiomi: En ese momento... no pues, yo... en sí yo pensaba que me lo merecía, porque yo decía "aqui estoy pagando lo que yo hice con mi mamá”. Todas las veces me lo recalcaba. Eso sí me lo decía cada rato "estoy pagando lo que hice con mi mamá, por eso él me trata así y me toca aguantarme porque me lo merezco y porque me toca pagar esto”.

Sara: En un momento sí fui muy precavida a tocar mis temas, de mis problemas personales. Porque me daba pena, porque nosotras las que vivimos eso nos creemos que somos la vergüenza, que “¿qué dirán de mí?" O sea, nos creemos menos, eso es lo que pensamos y por eso nos encerramos y no es así.

Ángela: Ya lo fui conociendo entonces, y más, y yo con mi hijo y yo sin trabajo, sin poder trabajar, ¿dónde dejo mi hijo entonces? um, o sea, como que tuve esa vida esa vida de "ay, me tocaba porque qué hago, dónde trabajo, si asi con niño no me reciben".

Así mismo, Payne (2000, p. 38) afirma que, en esa construcción narrativa, "vivimos de acuerdo a las historias que contamos a partir de nuestras vidas, en realidad estos relatos cincelan nuestra vida, la constituyen, la engloban”. En este sentido, se puede visibilizar cómo 
las mujeres se configuran a sí mismas de acuerdo a sus experiencias, otorgándose una identidad o un rol en su relación de pareja:

Ángela: Fui y soy falta de muchas carencias. Eso sí, una mujer luchadora y trabajadora.

Sara: Obvio que uno siente vergüenza, ser ignorante... es un área de ignorancia pienso yo. Eso ha sido... eso ha sido una humillación, muy grande.

Nanis: Muchas veces dicen que la mujer hace al hombre. Algo asi dicen, que la mujer hace al hombre. Entonces muchas veces las personas me decían que era por culpa mía que el papá de ellos era así, porque si yo hubiera sido una mujer diferente, por lo menos en el sentido del alcohol, de que yo le alcahueteaba que él tomara y eso, y pues dice la gente que eso sería diferente.

Se pueden ver discursos en el los cuales las mujeres se ven y se construyen a sí mismas, entorno a su experiencia y su relación de pareja, como "víctimas", "culpables en su rol como mujer", "con carencias", "ignorante". Ante estos significados construidos sobre las mujeres y su experiencia de violencia, Avellaneda (2012, p. 40) afirma que "la mujer que vive en violencia tiende a ubicarse en un lugar secundario en sus relaciones, percibiéndose poco central o protagónica en los sistemas en que vive, lo que se relaciona con la interiorización de un estereotipo femenino rígido", de esta manera, la mujer asume un rol inferior en lo que respecta al del hombre. Sin embargo, Thompson (citado en Feixas y Villegas, 2000, p. 139) afirma que el proceso narrativo y la construcción de "diversas clases de significados, pueden utilizarse para ayudar a las personas a desarrollar habilidades y asignar significados que sean más beneficiosos para ellos”. De esta manera algunas de las participantes narran haber configurado muchas de las concepciones que tenían:

Nanis: Pues es que he visto muchos casos de mujeres que se aferran a una sola persona, y todo se centra en esa persona, y que uno no cree que haya más personas por fuera del núcleo normalmente... de que de pronto, de pronto se interesen por uno. De que se interesen por uno en qué sentido, 
pues que estén pendiente de uno sin que esté ahi encima y encima ... y entonces eso fue lo que me hizo cambiar ese concepto de culpabilidad.

Ángela: Pues yo pienso que aún existen mujeres que se menos... para mí, se menosprecian. Porque en ese momento yo pienso que todas las mujeres en igual, o sea, buscamos equidad e igualdad, y algunas mujeres no piensan así porque es lo que el hombre dijo, y lo que él dijo se hace, y eso se tiene que hacer porque él es el hombre de la casa. Y yo en estos momentos no estoy de acuerdo con eso. Yo ya no estoy de acuerdo con eso.

Arias y Nieto (2014) señalan que a través de los relatos y narraciones que se construyen en situaciones de vulnerabilidad, las personas se encuentran unidas a las interpretaciones que realizan a partir de la narraciones dominantes, sociales, familiares y culturales. A partir de las interacciones con otros sistemas, culturas, sociedades se va configurando la identidad de pareja. Así mismo, en las construcciones narrativas entorno a su experiencia de violencia, las mujeres interpretan su realidad luego de la violencia como una liberación del poder al cual estaban sometidas por su pareja. Esto refleja la permeabilidad de los discursos de poder del hombre, quien se ve como superior y controlador de sus vidas:

Sara narra una situación en la que estuvo alejada de su pareja y relata: Yo me sentía libre de cierta manera, entonces yo trabajaba, me compraba mi ropa, la de mis hijos, la comida, pensaba por mi y no porque otro pensara por mí, que eso era lo que hacía ese señor en ese tiempo.

Ángela se refiere al rol del hombre en la relación: Ellos se creen con la autoridad de mandar porque aportan un dinero. O sea, yo lo veo así "iyo soy el que pongo!". Ellos piensan creerlo así, pero no es no porque "es que yo soy yo el que trabajo", "yo soy el que tiene”. Es más fuerte que una mujer, pero las mujeres... o sea, las mujeres tienen más. Más poder en todo porque nosotras podemos hacer varias cosas que ellos no hacen, muchas.

Nelly Narra cómo se siente luego de terminar su relación: Como libre, sí. No tengo que rendirle cuentas "que ay, que usted por qué llegó tarde", “ay, que”... no, no tengo que rendirle cuentas a nadie. Pero 
de resto me siento bien así como estoy ahorita. Estoy tranquila, salgo relajada, no tengo que estar preocupada "que esto", "que ay", "que fulano, que zutano", como estoy orita [sic.] estoy bien.

Con respecto a esto, Montes (2008, p. 12) concluye que "en nuestra sociedad, el poder del hombre sobre la mujer se manifiesta [...] en la esfera privada de las relaciones de pareja mediante la dominancia interpersonal". De esta manera, en las relaciones de pareja se construyen este tipo de discursos de poder que le confieren al hombre la soberanía sobre la mujer. Pero estos discursos no solo se configuran en la relación de pareja, la sociedad también actúa como reproductora de este tipo de discursos.

\section{Conclusiones}

A partir de las experiencias que narraron las participantes se identificó que todas vivieron diferentes tipos de violencia en su relación de pareja. Frente a sus situaciones, ellas comprendían los acontecimientos que atravesaron de manera única y diferente, y les daban su propio significado. Este proceso narrativo se conecta con lo escrito por Anderson (1997), quien menciona que los sistemas humanos son sistemas de generación de lenguaje y sentido. De esta manera, las participantes han construido su historia en medio de diversos sistemas.

En sus discursos se visibiliza la experiencia frente a las diferentes expresiones de violencia de pareja mediante la dirección de su relato mayormente hacia un tipo de violencia. A medida que las participantes narraban su historia, construían su realidad y le daban sentido a la misma. En este proceso de narrar, las participantes interpretaban sus experiencias configurando narrativas dominantes que se expresaban en sus relatos, en los cuales predominaba una construcción negativa de ellas mismas, en la que se representaban a ellas mismas sin recursos personales para afrontar la situación. Así mismo, las participantes construyeron, en medio de sus sistemas interrelacionales, narraciones o etiquetas saturadoras, como las de víctimas" o "ignorantes", que pueden considerarse un obstáculo que hace imposible transformar sus interacciones, en este caso, de pareja. Se pudo observar una 
dificultad recurrente en las participantes a la hora de identificar la violencia de tipo sexual, ya que había una asocian específica entre las prácticas sexuales y los roles establecidos dentro de la relación de pareja.

Dentro de las narrativas dominantes que construyeron las participantes frente a la experiencia de violencia, también se pudo entrever cómo ellas construían la idea de que la violencia era producto de elementos ajenos a su control, como el consumo de sustancias psicoactivas de sus parejas, o las pautas de crianza que experimentaron, entre otras.

En los relatos de las participantes se constata que las dinámicas de poder se construyen en diferentes contextos y dimensiones en los que es posible evidenciar la creencia en la supremacía del hombre sobre la mujer. Esta creencia se evidenció en diferentes ámbitos como el del funcionamiento familiar de las participantes y el de los referentes sociales con base en los que se construye el rol de la mujer. En algunos casos se identificó cómo la pauta de violencia del hombre hacia la mujer en los sistemas familiares emergió en cada generación como una pauta estructural repetitiva. Esta pauta hace que la familia co-construya discursos patriarcales y relaciones de poder con las que se confiere al hombre poder sobre la mujer. Esto favorece la relación de violencia y la construcción de roles que describen a las mujeres como inferiores en la interacción de pareja y en el funcionamiento familiar.

Estas construcciones de la violencia de pareja responden también a una expresión de la cultura patriarcal, aludiendo así al principio de recursividad de Morín (1990) y a los postulados de Anderson (1997). Estos autores afirman que estas experiencias son únicas y hacen parte de la construcción de la realidad, que ellas se crean y se reproducen a través de la cultura y contexto en el que cada individuo se encuentra. De esta manera, predomina la circularidad entre la cultura patriarcal existente en el contexto regional llanero y la violencia de pareja hacia la mujer: la cultura patriarcal y la violencia de pareja son elementos que retroactúan mutuamente y que se enmarcan en expresiones de poder del hombre hacia la mujer.

En la construcción de los relatos se evidenció la emergencia de nuevas formas en las que las mujeres se comprenden a sí mismas en torno a las relaciones de pareja. Se encuentran 
así, en las narraciones, relatos alternos acerca del problema y su futuro. Las narraciones que predominaron al finalizar los encuentros expresan la intención de abandonar la repetición de interacciones violentas en sus relaciones actuales o futuras. Este proceso es posible en la construcción narrativa, la cual permite la emergencia de relatos alternos que, de acuerdo con White (2004), permiten a los sujetos experimentar separación de su historia y quedar en libertad de explorar otras ideas que podrían incorporar a su vida.

El fenómeno de las relaciones de poder se complejiza en diferentes sistemas y fue posible observarlo en los discursos de las participantes, quienes mencionaron que entre los diferentes escenarios en los que se expresa el uso del poder se encuentran: relaciones laborales, funcionarios públicos, el conflicto armado, entre otras. Con respecto al conflicto armado, algunas narran experiencias difíciles a las que fueron sometidas, como el desplazamiento y la violación sexual.

Se pudo apreciar que las participantes conocían la existencia de instituciones que, apegándose a lo establecido en la legislación colombiana, buscan proteger los derechos y la integridad de las mujeres. Sin embargo, no todas las participantes buscaron apoyo en estas. Algunos relatos muestran, por el contrario, el rechazo hacia dichas instituciones debido a las construcciones que han hecho acerca de ellas. Cabe resaltar el discurso que trasmiten las instituciones en la búsqueda de esa renegociación de poder. Predomina en ese discurso la etiqueta de víctima para las mujeres que experimentan alguna situación de violencia. Esto hace que, en algunos casos, la emergencia de construcciones identitarias diferentes a la de "ser víctima" no tenga lugar para las mujeres víctimas de violencia de pareja.

\section{Referencias}

Acosta, B., y Cardozo, D. (2014). Construcción identitaria en una pareja que es remitida por motivo de violencia intrafamiliar, narrando situaciones críticas (tesis de pregrado). Bogotá: Universidad Santo Tomás.

Agencia de los Derechos Fundamentales de la Unión Europea. (2014). Violencia de género contra las mujeres: una encuesta a escala de la UE. Recuperado de http://webcache.googleusercontent.com/ 
search?q=cache:iOsAWJekgqMJ:fra.europa.eu/sites/default/files/fra2014-vaw-survey-factsheet_es.pdf+ycd=1yhl=esyct=clnkygl=co

Amigot, P. (2005). Relaciones de poder, espacio subjetivo y prácticas de libertad: análisis genealógico de un proceso de trasformación de género (tesis de doctorado). Barcelona: Universitat Autònoma de Barcelona. Recuperado de http://www.tesisenred.net/bitstream/ handle/10803/5443

Amurrio, M., Larrinaga, A., Usategui, E., y Del Valle, I. (2010). Violencia de género en las relaciones de pareja de adolescentes y jóvenes de Bilbao. Zerbitzan, 47, 121-133.

Anderson, H. (1997). Conversación lenguaje y posibilidades. Un enfoque posmoderno de la terapia. Buenos Aires: Amorrortu editores.

Aponte, R. (2016). Hermenéutica y ciencias sociales: a propósito del vínculo entre la interpretación de la narración de Paul Ricoeur y el enfoque de investigación biográfico-narrativo. Análisis revista colombiana de Humanidades, 49 (90), 205-228. Recuperado de http://revistas.usta. edu.co/index.php/analisis/article/view/3229

Arias, I., y Nieto, D. (2014). Construcción y re-construcción narrativa de la identidad en parejas, que posibiliten versiones generativas frente a relatos vulnerantes (tesis de pregrado). Bogotá: Universidad Santo Tomás. Recuperado de http://repository.usta.edu.co/handle/11634/3325

Avellaneda, M. (2012). Mujeres profesionales y sus narrativas de violencias en las relaciones de pareja (tesis de maestría). Universidad Nacional de Colombia. Recuperado de ttps://drive.google.com/file/ d/0B644z5PkFsJpTHFuWFRsT3pnb3c/view

Chávez, A. (2013). Violencia sexual en la pareja como práctica de violencia de género: experiencias de mujeres a través de relatos de vida en Estación Central (tesis de grado). Universidad de Chile. Recuperado de http://www. ciegchile.com/wp-content/uploads/2014/05/Violencia-sexual-en-lapareja-como-pr\%C3\%A1ctica-de-violencia-de-g\%C3\%A9nero.pdf

Clandinin, J., Debbie, P., y Murray, A. (2007). Navigating Sites for Narrative Inquiry. SAGE, 58(1), 21-35. Recuperado de https://www.researchgate. net/publication/249704796_Navigating_Sites_for_Narrative_Inquiry

Contreras, R. (06 de agosto del 2016). La normalización de la violencia. Excélsior. Recuperado de http://www.excelsior.com.mx/opinion/raulcontreras-bustamante/2016/08/06/1109294

Corsi, J. (comp.), (1994). Violencia familiar. Una mirada interdisciplinaria sobre un grave problema social. Buenos Aires: Paidós.

De Lujan, M. (2013). Violencia contra las mujeres y alguien más (tesis de doctorado). Recuperado de http://roderic.uv.es/bitstream/ handle/10550/29006/Tesis\%20completa.pdf

Echeverría, R. (2005). Ontología del lenguaje. Chile: Lom Ediciones S.A.

Feixas, G., Muñoz, D., Compañ, V., y Montesano, A. (2016). El modelo sistémico en la intervención familiar. Universidad de 
Barcelona. Recuperado de http://diposit.ub.edu/dspace/ bitstream/2445/31584/6/Modelo_Sistemico_Enero2016.pdf

Feixas, G., y Villegas, M. (2000). Constructivismo y psicoterapia. (3ra. Ed.). España: Editorial Desclée De Brouwer.

Galeano, A., Jaimes, F., y Palacio, L. (2014). Prácticas dialógicas que movilizan relatos identitarios y reconfiguran ecológicamente pautas de violencia en la pareja (tesis de maestría). Bogotá: Universidad Santo Tomás. Recuperado de http://repository.usta.edu.co/handle/11634/457

Gómez, L., Murad, R., y Calderón, M. (2013). Historias de violencia, roles, prácticas y discursos legitimadores. Violencia contra las mujeres en Colombia 2000-2010. Recuperado de https://www.minsalud.gov.co/ sites/rid/Lists/BibliotecaDigital/RIDE/INEC/INV/7\%20-\%20 VIOLENCIA\%20CONTRA\%20LAS\%20MUJERES\%20EN\%20 COLOMBIA.pdf

González, H., y Fernández, T. (2010). Hombres violentados en la pareja. Jóvenes de Baja California, México. Culturales, 2(2), 129-155.

Recuperado de http://www.redalyc.org/articulo.oa?id=69432742006

González, O., y Serna, A. (2004). Entre el estilo y el método: el estatuto de la narrativa en la comprensión de los universos psico-socio-culturales. Diversitas: perspectivas en psicología. 1(1), 63-78. Recuperado de http:// www.redalyc.org/articulo.oa?id=67910107

Hernández, A. (2007). Trascender los dilemas del poder y del terapeuta como experto en la psicoterapia sistémica. Univ. Psychol, 6(2), 285-293.

Huchim, A., y Reyes, R. (2013). La investigación biográfico-narrativa, una alternativa para el estudio de los docentes. Revista electrónica Actualidades investigativas en educación, 13(3), 1-27. Recuperado de http://www.redalyc.org/articulo.oa?id=44729878019

Instituto Nacional de Medicina Legal y Ciencias Forenses. (2017). Estudio del comportamiento de la violencia intrafamiliar realizado en Colombia. Recuperado de http://www.medicinalegal. gov.co/documents/10180/188820/FORENSIS+2013+7+violencia+intrafamiliar.pdf/dd93eb8c-4f9a-41f0-96d7-4970c3c4ec74

Lavilla, S., Cabrero, A., y Jimeno, A. (2011). Perspectivas psicológicas de la violencia de genero. Recuperado de https://www.aragon.es/ estaticos/GobiernoAragon/Organismos/InstitutoAragonesMujer/ Documentos/perspectivas\%20psicologicas.pdf

López, D. (2016). Conoce las cifras de violencia doméstica y empoderamiento de la mujer en américa latina. [Entrada de blog]. Recuperado de https://blogs.iadb.org/salud/2016/03/04/ empoderamiento-de-la-mujer/

Martínez, C. (2014). Monografía sobre violencia de pareja desde un enfoque sistémico. Recuperado de https://www.colibri.udelar.edu.uy/ bitstream/123456789/5326/1/MARTINEZ\%2C\%20CAROLINA.pdf 
Molina, J., y Moreno, H. (2015). Percepción de la experiencia de violencia doméstica en mujeres víctimas de maltrato de pareja. Universitas. Psychologica, 14(3), 997-1008. Recuperado de http://www.scielo.org.co/ pdf/rups/v14n3/v14n3a17.pdf

Morín, E. (1990). Introducción al pensamiento Complejo. México: Gedisa.

Montes, B. (2008). Relaciones de poder y dominancia. El poder del hombre sobre la mujer. Research Gate. Recuperado de https://www. researchgate.net/publication/246547694_Relaciones_de_poder_y_ dominancia_El_poder_del_hombre_sobre_la_mujer

Noseda, J. (2015). Violencia sexual en tu propia cama: la agresión sexual en pareja. [Entrada de blog]. Recuperado de http://www.eldinamo. $\mathrm{cl} / \mathrm{blog} /$ violencia-sexual-en-tu-propia-cama-la-agresion-sexual-enpareja/

Organización Mundial de la Salud [OMs]. (2002). Informe mundial sobre la violencia y la salud. Recuperado de http://iris.paho.org/xmlui/ bitstream/handle/123456789/725/9275315884.pdf?sequence=1

Organización Mundial de la Salud [омs]. (2013). Comprender y abordar la violencia contra las mujeres. Recuperado de http://www.who.int/ reproductivehealth/topics/violence/vaw_series/es/

Organización Mundial de las Naciones Unidas (2001). Declaración sobre la eliminación de la violencia contra la mujer. Recuperado de http://www. ohchr.org/SP/ProfessionalInterest/Pages/ViolenceAgainstWomen. aspx

Payne, M (2000). Terapia narrativa. Una introducción para profesionales. España: Paidós.

Perrone, R., y Nannini, M. (2000). Violencia y abusos sexuales en la familia: Una visión sistémica de las conductas sociales violentas. México: Paidós.

Quintanilla, C. (2014). Análisis sociológico de la violencia doméstica. De un problema individual a un problema social, la violencia doméstica como problema estructural. [Congreso de Violencia Doméstica]. Recuperado de www.poderjudicial.es/stfls/PODERJUDICIAL/ DOCTRINA/FICHERO/10OVDCON-1_1.0.0.pdf + ycd=3yhl=esyct=cln $\mathrm{kygl}=\mathrm{cO}$

Quintela, M., Arandia, M., y Campos, P. (2004). De la comunidad al barrio: violencia de pareja en mujeres migrantes en Sucre. La Paz, Bolivia: Fundación PIEb.

Ramírez, N. (2015). Mujeres violentadas y el proceso de empoderamiento: una lectura psicosocial desde el centro de atención a víctimas de la Fiscalía General de la Nación (tesis de grado). Recuperado de http://stadium.unad.edu. co/preview/UNAD.php?url=/bitstream/10596/3536/1/43556514.\%20 pdf.pdf

Ramírez, N., y Posso, M. (2012). Relaciones de poder entre hombres y mujeres: su influencia en el desarrollo de enfermería. Reflexiones, 33(1), 26-31. 
Vera, J. (2015). Antropología y "estudios de la violencia" en Colombia: en busca de una perspectiva crítica. Revista Colombiana de Antropología, 51(1), 245-269. Recuperado de http://www.scielo.org.co/pdf/rcan/ v51n1/v51n1a10.pdf

Villareal, A. (2001). Relaciones de poder en la sociedad patriarcal. Revista electrónica Actualidades investigativas en educación, 1(1), 1-18. Recuperado de http://www.congresoed.org/wp-content/uploads/2014/10/ Relaciones-de-poder-en-la-soc-patriarcal-pdf

White, M. (2004). Guías para una terapia familiar sistémica. España: Editorial Gedisa, S.A

Zuluaga, B. (2007). Una Mirada de la Familia desde el Enfoque Sistémico. Recuperado de: https://beatrizzuluaga.wordpress.com/2007/02/09/ las-relaciones-de-pareja-y-su-influencia-en-los-hijos 